\title{
Exploring the process of management system implementation: a case of Six Sigma
}

\author{
Jeroen De Mast \\ Statistics and Actuarial Science, University of Waterloo, Waterloo, Canada \\ Bart A. Lameijer \\ Business Analytics, University of Amsterdam, Amsterdam, The Netherlands \\ Kevin Linderman \\ Supply Chain and Information Systems, Smeal College of Business, \\ The Pennsylvania State University, Pennsylvania, USA, and \\ Andrew Van de Ven \\ Strategic Management and Entrepreneurship, Carlson School of Management, \\ University of Minnesota, Minneapolis, Minnesota, USA
}

\begin{abstract}
Purpose - The purpose of this study is to discover the learning mechanisms and temporal dynamics of implementing systems (Six Sigma) as it unfolds over time.

Design/methodology/approach - The data come from a European engineering company that was implementing a Six Sigma-based quality management system (QMS) over a seven-year period. The analysis is based on an event-sequence reconstruction of the implementation process as it unfolded over time and discovers four different learning mechanisms that emerged: programmatic, persistent, adaptive and dialectical learning mechanisms. The research follows a process design study, where the authors study how the process unfolds over time.

Findings - Much of the literature on implementing management systems suggests that implementation follows a prescribed sequence of "turn-key" steps. However, the findings show that only $40 \%$ of all events were driven by prescribed "turn-key" generic practices, while $56 \%$ of events required constructing new practices via adaptive and dialectical learning. Moreover, the implementation process did not proceed in a linear programmatic fashion, but instead followed a punctuated equilibrium pattern, which alternated between periods of incremental change and major organizational change. The study also found that implementation required changing many complementary organizational structures and practices that were interdependent with the management system (i.e. Six Sigma). By understanding the implementation process, managers can better assess the time and effort involved, better adapt the system to their situated context and predict critical junctures where implementation could break down.

Originality/value - This research complements the few studies that have examined the process of implementing management systems. Most studies examine factors or conditions that result in implementation success (the what of implementing systems), but few examine the process of implementation and the learning that takes place during implementation (the how of implementing systems), which is a complex nonlinear process that involves different modes of learning.
\end{abstract}

Keywords Learning, Quality management, System implementation, Punctuated equilibrium, Six Sigma, Process study

Paper type Research paper

(C) Jeroen De Mast, Bart A. Lameijer, Kevin Linderman and Andrew Van de Ven. Published by Emerald Publishing Limited. This article is published under the Creative Commons Attribution (CC BY 4.0) licence. Anyone may reproduce, distribute, translate and create derivative works of this article (for both commercial and non-commercial purposes), subject to full attribution to the original publication and authors. The full terms of this licence may be seen at http://creativecommons.org/licences/by/4.0/ legalcode

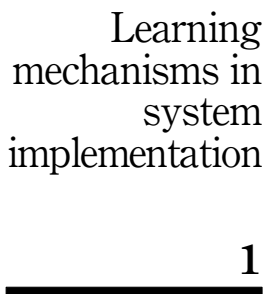

Received 23 September 2020 Revised 2 April 2021 28 October 2021

Accepted 19 November 2021 
IJOPM

42,13

\section{Introduction}

To what extent does implementing a management system involve installing "turn-key" prescriptions from best practices, and to what extent is it a trial-and-error process that involves adapting the system and the organization? Operations managers face the challenge of implementing various systems such as Six Sigma (Shafer and Moeller, 2012; Swink and Jacobs, 2012), Lean (Netland et al., 2015) and enterprise resource planning (ERP) (Tenhiälä and Helkiö, 2015), to name a few. These systems hold the promise of improving performance by creating fundamental changes to the organization, but can also lead to implementation failure, which undermines the benefits.

To help guide implementation, organizations typically rely on roadmaps or templates that consist of codified best practices (e.g. Baldrige Award criteria), captured lessons learned from leading organizations (e.g. General Electric's implementation of Six Sigma) or procedural steps and guidelines from vendors and consultants. These roadmaps may give the impression that implementing a management system is a straightforward process of adopting the best-practice prescriptions (Lameijer et al., 2017). However, scholars recognize the importance of fitting management systems to their situated context. For example, Zhang et al. (2012) showed that quality management systems (QMSs) need to fit their context to achieve the highest level of operational performance, and Canato et al. (2013) also showed that a lack of fit can lead to implementation failure. This suggests the need to adapt management systems to the organizational context (Jensen and Szulanski, 2007; Ansari et al., 2010; Bresman, 2013), and there are limits to adopting turn-key prescriptions. However, scholars have not studied how the implementation and adaption process occurs (Ivanova et al., 2014).

The purpose of this study is to empirically discover the process and degree to which implementing a new QMS follows a "turn-key" programmatic process versus a constructive and adaptive process. The practitioners' literature portrays QMS implementation as a straightforward process of implementing best-practice prescriptions (Lameijer et al., 2017, 2021). Some of the academic literature echoes this perspective, for example, Chakravorty (2009) attributes implementation failure to either the organization's failure to adhere to the prescribed model or imperfections in the model itself. In addition, organizations often rely on best-practice prescriptions when implementing systems. For example, Braunscheidel et al. (2011) found evidence of "mimetic isomorphic mechanisms" when organizations implement systems. That is, organizations copied behaviors of other organizations that appeared to have successfully implemented a QMS. If this portrayal is realistic, implementation should be a copy and paste exercise, where the implementation involves adopting generic practices from a template. Templates do in fact capture codified knowledge from other organizations. However, this research takes the perspective that implementing systems also involves making adaptations to some of the practices so that they better the organization's specific context (Jensen and Szulanski, 2007; Ansari et al., 2010; Bresman, 2013; Powell and Coughlan, 2020; Netland et al., 2021). This in itself is a complex learning process of understanding how to capture knowledge from templates while also adapting the system and organization to fit the context.

The literature on organization change discusses implementing management system, but there is no consensus about the basic nature of the change processes (Stouten et al., 2018; Bamford and Daniel, 2005). Scholars such as Jensen and Szulanski (2007), Ansari et al. (2010) and Bresman (2013) recognize the importance of fitting systems to the organizational context, but they frame the essential nature of the implementation process as adhering to a standardized template. Typically, such prescriptive models specify a sequence of deployment steps that apply to a wide variety of organizational change interventions, and do not fully consider how and when organizational learning should occur to adapt the system. Change models based on organizational learning theories have also not been fully considered in the literature (Stouten et al., 2018). This research contributes to our understanding of 
organizational learning during the implementation of a QMS (i.e. Six Sigma) in a European division of an engineering company (EuroDiv). During the implementation, EuroDiv faced challenges of adopting the prescriptions of Six Sigma while also adapting Six Sigma and the organization to make it work. Our three primary research objectives are to understand: "How does the process of implementing a QMS unfold over time? To what extent does the implementation process follow prescriptive learning mechanisms where they implement programmatic and turn-key recommendations, and to what extent does it follow constructive learning mechanisms where adaptations are developed to fit the organizational context?"

Fundamental to our process research design (Langley et al., 2013) is the concept of exploitative abduction (Bamberger, 2018), i.e. the systematic collection of the facts, followed by an attempt to identify a framework which explains the pattern of facts identified. The case of EuroDiv offers uniquely rich data, based on which we can reconstruct the implementation process as it unfolded and the learning mechanisms that drove change. The analysis shows that the implementation process was driven as much by constructive learning mechanisms $(56 \%)$ as by prescriptive learning mechanisms $(40 \%)$. Second, the lessons that EuroDiv learned were more fundamental and transformational in nature. The implementation entailed an examination and change of other essential organizational characteristics, not directly related to Six Sigma, but interdependent with it, and implementing the system became a catalyst to address deeply entrenched organizational patterns. These entrenched patterns were hidden or ignored when the initiative started, and Six Sigma implementation exposed or even amplified them. Finally, deep learning did not seem to occur unless there was a need for it. This resulted in the implementation process following the pattern of a punctuated equilibrium, with alternating periods of incremental adaptation and periods of transformational changes. Our data suggest that the dynamics driving this pattern are entrenched organizational system conditions that interfere with the Six Sigma principles, thereby frustrating the implementation and resulting in a build-up of tension. Important breakthroughs in the implementation did not occur until enough tension had built up to overcome complex equilibrium (status quo) behavior. These findings represent important discoveries in the literature on implementing management systems. Our findings suggest that the implementation of management systems should not strictly follow programmatic and generic templates, but instead, should navigate a learning process between implementing the prescriptions and templates of the system and constructing solutions that adapt the system and organization to better fit together.

In the next sections, we formulate the theoretical framework from which we designed our study, which leads to Section 3 where we present the data sources, coding scheme and an introduction to the case. Section 4 presents findings and places these in relevant theories in management, resulting in a process theory of QMS implementation. Sections 5 and 6 conclude the paper by discussing the results and summarizing the implications.

\section{Literature review}

Managing organizations comprise both overseeing day-to-day operations (exploitation) and driving improvement and innovation (exploration) to ensure business continuity. To do so, managers select and implement existing standards, best practices and proven organizational configurations called management systems.

\subsection{Management system implementation mechanisms}

Many types of management systems exist to manage an organization' workflow, financial assets and information. However, implementing such management systems typically follow similar programmatic steps, where existing practices are phased out and new prescribed practices are $\begin{array}{r}\text { mechanisms in } \\ \text { system } \\ \text { implementation } \\ \mathbf{3} \\ \hline\end{array}$
Learning 
IJOPM

42,13

implemented (Ivanova et al., 2014). The literature on organizational change and development reveals that little is known about the actual change process of involved in implementing systems, where most of the academic writing relies on expert opinion, which results in prescriptive and programmatic change models for practitioners to follow (Stouten et al., 2018). Existing research needs to recognize the implementation of systems as a learning process that drives organizational change (Boonstra, 2008). Nevertheless, organizational learning-based change models, such as three-act drama (Tichy and Devanna, 1986) and punctuated equilibrium (Tushman and Romanelli, 1985), have not been fully examined by scholars (Stouten et al., 2018).

The literature on organizational learning provides a useful theoretical lens to understand the underlying mechanisms that drive change when implementing a system. The behavioral theory of the firm assumes organizations develop by the learning that takes place as an activity sequence, where actors undertake a course of action, followed by observing the outcome of those actions, and then making adjustment for future actions (Argote and MironSpektor, 2011; Levitt and March, 1988). Van de Ven and Poole (1995) and Poole (2004) developed a typology of change mechanisms and classify them as either prescriptive or constructive learning mechanisms.

Prescriptive mechanisms drive the implementation when change events are prescribed by a given program. The program could follow templates from other companies or be imposed by consultants. Also later in the process, if confronted with a problem or issue, the organization turns to authoritative resources (consultants, textbooks, templates, best practices) to guide their implementation rather than developing their own solution. Prescriptive mechanisms include programmatic behavior ("follow instructions", "accept others' vision on authority") and persistent behavior ("stick to the program even if it appears not to work well"). Forms of prescriptive mechanisms are alternatively called compulsory behavior (Huber, 1991; Noe et al., 2014) and regulated change (Van de Ven and Sun, 2011).

Constructive mechanisms drive organizational change when the implementation process emerges and develops as it unfolds. In this model, an implementation team discovers new insights as part of the implementation process and invents and constructs new solutions themselves. Constructive mechanisms include various forms of learning behavior, such as adaptive and dialectical learning (Van de Ven and Poole, 1995).

This classification of organizational change mechanisms provides the theoretical basis for developing a better understanding of the implementation process of QMSs, which is introduced next. The implementation of quality systems may employ both prescriptive mechanism and constructive mechanisms.

\subsection{Quality management system implementation processes}

Several organizations have faced challenges in implementing quality systems, which may be due to the implementation process. QMSs are defined as "formalized systems that document processes, procedures, and responsibilities for achieving quality policies and objectives" (American Society for Quality, 2021). Common contemporary manifestations of QMS's include Six Sigma (Shafer and Moeller, 2012; Swink and Jacobs, 2012), Lean (Netland et al., 2015, 2021) and ISO 9001 (Ivanova et al., 2014), to name a few. However, these systems are related to a vast array of both production and quality systems that have been developed over time. Production systems typically comprise technological elements (e.g. machines, software and tools) and organizational elements (e.g. division of tasks and mandates, flow of information and planning and control of production). Manifestations of such production systems are for example material requirements planning (MRP), kanban (JIT), optimized production technology (OPT), flexible manufacturing systems (FMSs), theory of constraints (TOC) (Chakravorty and Atwater, 1996) and the Toyota Production System (TPS) and Lean production (LP) (Pegels, 1984; Bhamu and Sangwan, 2014). 
Continuous improvement is an important element of production systems. The concept of continuous improvement stems from the American discipline of statistical quality control (Shewhart, 1931) and the Japanese "Kaizen" (Imai, 1986). Continuous improvement is about "striving for the best in quality and performance in all operations of the business" (Hammer, 2004, p. 85), and companies typically choose to organize this by QMS implementation (Lameijer et al., 2021). Despite the fact that these QMSs (e.g. Lean, Six Sigma, ISO 9001 and total quality management) have intersystem differences (i.e. focus on-variation vs efficiency, documentation vs expertise and statistics vs visualization) and similarities (i.e. focus on operational excellence, parallel meso-organizations, processes as unit of analysis, etc.), the process of implementing these systems in organizations is comparable (Lameijer et al., 2021). As a result, we believe that this research has implications for a broader array of quality systems in operations management.

QMSs offer techniques for process improvement, often rather similar to prior approaches in quality management $(\mathrm{QM})$, but also offer an organizational structure, a structured improvement method and metrics for managing the improvement initiative (Zu et al., 2008). Research on QMS implementation typically adopts (1) the project or (2) the organizational level as unit of analysis (McAdam and Lafferty, 2004; Schroeder et al., 2008; Zu et al., 2008; Anand et al., 2009; Nair et al., 2011). Much of the work in these QMSs gets done on a project-by-project basis, aimed at improving processes, products or services. These projects are essentially structured routines to solve problems and are characterized as meta-routines - routines to change routines (Peng et al., 2008). Dedicated improvement specialists lead these projects, and research shows that project goals (Linderman et al., 2003, 2006; Nair et al., 2011), project team leader experience (Easton and Rosenzweig, 2012) and the team leader's social capital (Easton and Rosenzweig, 2015) can influence the success of such projects.

Research on QMS implementation at the organizational level is dominated by variance studies looking for factors that enable or inhibit successful implementation (e.g. Linderman et al., 2006; Anand, 2009; Nair et al., 2011; Zhang et al., 2012; Easton and Rosenzweig, 2012; Jacobs et al., 2015). No research, to our knowledge, has examined how the process of implementation actually unfolds over time to better understand their outcomes. QMS implementation holds the promise of improving performance by creating fundamental changes to the organization, its processes and the way people execute their work, but can frequently result in implementation failure (McLean et al., 2017; Scherrer-Rathje et al., 2009). To prevent such failure, the literature proposes a variety of implementation guidance to support management decision-making in the form of lessons from case studies (e.g. Hirzel et al., 2017; Pierce and Rich, 2009; Nonthaleerak and Hendry, 2008) and implementation and maturity models (Lameijer et al., 2021).

Lameijer et al. (2017, 2021) systematically studied the large volume of QMS implementation and maturity models in both academic and practitioners' literature. With almost no exception, these models describe the implementation process as driven by programmatic patterns. The implementation process is portrayed as following a preconceived, step-wise roadmap. The desired end-state of implementation is not something that the organization needs to discover. Rather, it is given (not open to modification) and generic (copied from best practices such as Baldrige Award winners, Toyota and General Electric). Typically, the change process is portrayed as one of indoctrination (Ouchi, 1979). The process is typically described in terms of "early believers" and "initial visionaries" who should be mobilized to achieve "buy-in" from the majority of the organization, while actors who have reservations or different views are framed as "resistors to change." This portrayal of the implementation process as largely programmatic is mirrored in the academic literature by authors such as Chakravorty (2009) and Braunscheidel et al. (2011), and also beyond the QM literature, many studies of the transfer of practices such as Jensen and Szulanski (2007) and Danese et al. (2017) describe such processes as 
IJOPM

42,13 programmatic and driven by prescriptive templates, providing a basis for the first research question.

RQ1. To what extend are longitudinal QMS implementation processes based on prescriptive mechanisms, characterized by programmatic implementation of practices?

In contrast, we argue that QMSs need to make adjustment to the specifics of an organization adopting it to overcome technical, cultural or political misfit (Ansari et al., 2010, Zhang et al., 2012; Swink and Jacobs, 2012). In that case, the implementation team needs to deviate from generic prescriptions and implementation plans and construct new solutions by learning what does and does not work for their context. Even though prior research did recognize the importance of organizational learning in QMS implementation processes (Kerrin, 1999; Linderman et al., 2004; Netland et al., 2021), none of them provided a description and theory of how organizations actually learn over time (i.e. the mechanisms or patterns at play) in QMS implementation processes, leading to our second research question.

RQ2. To what extend are longitudinal QMS implementation processes based on constructive mechanisms, characterized by constructive learning behaviors?

\section{Research methods}

Because our study examines a process question about how QMS implementation unfolds over time, we adopt a longitudinal process study research design (Langley et al., 2013). Process studies focus on temporal questions of how things emerge, grow and develop by examining progressions and patterns in events or activities over time (Van de Ven, 2007). Unlike variance studies that tend to examine multiple cases at a point in time (Mohr, 1982), in process studies, the unit of analysis is a temporal event, and sample size is determined by the number of coded events (220 in our case) observed over time in an organization to describe and explain a process pattern. It is important to note that EuroDiv saw the implementation process through to a mature stage. Implementations that are abandoned early or that fade away are likely to reveal only a part of the patterns that we reconstruct and discuss in this case.

\subsection{Case presentation}

This research is based on a longitudinal study from 2007 to 2014 of 220 coded events dealing with the implementation of Six Sigma in the European division of an engineering company, which we will call EuroDiv for confidentiality reasons. In this section, we briefly describe the case and then explain the data collection, analysis and the research process.

EuroDiv designs and manufactures high-volume electronic devices, mainly for the automotive industry. The company has its headquarters in the USA and production sites in Asia, Latin America and Europe. This study focuses on the European division. EuroDiv consists mainly of a large product development and engineering group, besides some smaller departments for marketing and sales and a small production site in Eastern Europe. The group designs devices customized for particular car models on the basis of requirements defined by the original equipment manufacturer. This development process takes place in the form of projects that EuroDiv refers to as NPD (new product development) projects. Prior to implementing a Six Sigma-based QMS, EuroDiv had been successful and profitable. But their customers, especially the German car manufacturers, insisted on better and more structured control of the quality and reliability in the design of their products. One of their German customers expressed their concern by talking about "Zufällig gute Produkte" (good products 
due to good luck), a catchphrase that would later be used frequently to motivate the Six Sigma initiative. This pressure led to the start of the Six Sigma initiative at EuroDiv in 2007. The focus in EuroDiv was on product development. Applications of Six Sigma in product development are often called Design for Six Sigma, and this was also the name originally used by EuroDiv for the initiative. Originally, EuroDiv described the purpose of the Six Sigma initiative as a way to achieve "low ppms" (defective parts per million units produced). By improving engineering rigor, EuroDiv wanted to design better products that had lower failure rates during manufacturing and in the field.

EuroDiv's initial deployment approach for Six Sigma followed the blueprints from other companies and consultants. The Six Sigma deployment process unfolded in a sequence of planning waves, which occurred at a rate of one or two per year. Practically, a wave represents a new group of participants entering the Six Sigma training program, but each planning wave also represents a moment in the implementation process where the Six Sigma deployment team would examine and adjust their deployment plans. Concurrent to the training, trainees apply what they learn in their first Six Sigma projects. These projects are selected to improve processes or product designs based on a limited number of characteristics. Projects are scoped such that they can be completed within six months, before the next wave participants entering the Six Sigma training. Project champions monitor the progress of the Six Sigma projects by conducting project reviews. The deployment team at EuroDiv was named the Six Sigma core team, and they were responsible for the deployment and overall success of Six Sigma implementation. The core team reported to a steering team, consisting of top managers of EuroDiv.

\subsection{Event coding model}

Our study analyzes the sequence of events through which the QMS implementation process unfolded. Following Van de Ven et al. (2019) and other process studies, we model events in terms of an action, an outcome and a response. This model allows us to analyze the prescriptive and constructive mechanisms driving the process and has its roots in the behavioral theory of learning (Levitt and March, 1988; Argote and Miron-Spektor, 2011; Schwab and Miner, 2008). This theory views learning as an activity sequence where the deployment team undertakes a course of action (A1), which results in an outcome (O1) or feedback from the environment. The deployment team interprets and assesses the outcome (O1) of action (A1), and the last component of the event is the response or subsequent action (A2) that they undertake. Reconstructing the implementation process as a sequence of such action-outcome-response events allows us to analyze how the deployment team works, how they evaluate the effects of their actions and how they respond. This in turn allows us to analyze to what extent the process follows prescriptive or constructive patterns. Depending on how a response $\mathrm{A} 2$ is related to the anteceding action $\mathrm{A} 1$ and outcome $\mathrm{O} 1$, we code events as one of four patterns. Two of them, adaptive and dialectical learning, are manifestations of a constructive change mechanism. The other two, programmatic and persistent, are manifestations of a prescriptive change mechanism.

3.2.1 Constructive change mechanisms. Following the behavioral theory of learning (Levitt and March, 1988; Schwab and Miner, 2008), we classify events as adaptive learning when a course of action (A1) has a negative outcome (O1), and subsequently, the deployment team changes the course of action and tries out something new. For example, the organization starts with a few pilot Six Sigma projects, sees what works and then adjusts procedures on the basis of the results. Adaptive learning assumes that the deployment team's members agree on the assessment of outcomes (O1) for making future adjustments (A2) to implementing the system.

However, behavioral learning theory does not address instances when organizational actors have different logics, value systems or interpretative schemes and consequently may 
IJOPM

42,13

8 disagree on the assessment of the outcome (O1). We classify events as dialectical learning when there is dispute about the evaluation or interpretation of the outcomes (O1) and when dialogue forges a resolution (A2) that synthesizes the conflicting perspectives. In dialectical learning, the event sequence consists of a thesis opposed by an antithesis, followed by a synthesis (Van de Ven and Poole, 1995; Van de Ven et al., 2019). This pattern is comparable to conflictive change in Van de Ven and Sun (2011). In both adaptive and dialectical learning, the deployment team finds negative or at least disputed outcomes and responds by departing from the initial program and trying out new ideas instead.

3.2.2 Prescriptive change mechanisms. We classify events as programmatic behavior when a course of action (A1) has a positive outcome (O1), and the response (A2) is to continue following the same course. Programmatic mechanisms are alternatively called compulsory behavior (Huber, 1991; Noe et al., 2014) and regulated change (Van de Ven and Sun, 2011).

The last pattern, persistent behavior, occurs when the deployment team continues a course of action even when the outcome assessment (O1) is negative. This pattern describes nonlearning behavior (Van de Ven et al., 2019). This could happen when the negative outcomes are ignored or denied. It could also happen that the negative outcomes are acknowledged, but the deployment team abandons the issue for lack of time or fails to formulate a real response that is more than an uncommitted appeal or call to action. Finally, persistent behavior could also happen when the deployment team still believes in the validity of action A1, despite its negative outcome O1, and that perseverance will suffice to get better outcomes in due time.

\subsection{Data collection and coding procedure}

The lead author observed the implementation process as a participant-as-observer from 2007 to 2014. In addition, EuroDiv maintained detailed records of the implementation process. Our reconstruction of the sequence of events came from records kept by EuroDiv when the process unfolded. This was based on the following sources.

(1) Meeting minutes and management presentations of the Six Sigma core team (48 documents).

(2) Bi-weekly Six Sigma newsletter (144 documents). The Six Sigma core team edits this periodical, which reports key initiatives, events and challenges in the Six Sigma deployment effort. This report provides a reliable, continuous stream of information. We analyzed all 144 available editions from January 2007 until the end of 2014.

Figure 1 gives an overview of the research process. The first round of analysis followed the event sequence method (Poole et al., 2000), where the archival data were used to reconstruct a chronological representation of the actions taken by the deployment team. Events were modeled in the action-outcome-response sequence as discussed above, where the deployment team takes actions (A1), assesses the outcome of those actions (O1) and then takes a subsequent response (A2). In reconstructing the implementation process, we identified events by first searching in the archival sources for occasions where the Six Sigma core team evaluated whether some course of action was going well or not. From there, we established

(1) Actions (A1): what were the earlier decisions, policies and initiatives being evaluated?

(2) Outcomes assessment (O1): were the outcomes evaluated as either positive (the action goes well and without negatives; this helps the Six Sigma initiative forward) or as negative (the course of action has negative outcomes)? We also established whether the deployment team univocally agreed on the outcome, or whether there was ambiguity or dispute in the evaluation of the outcome. 


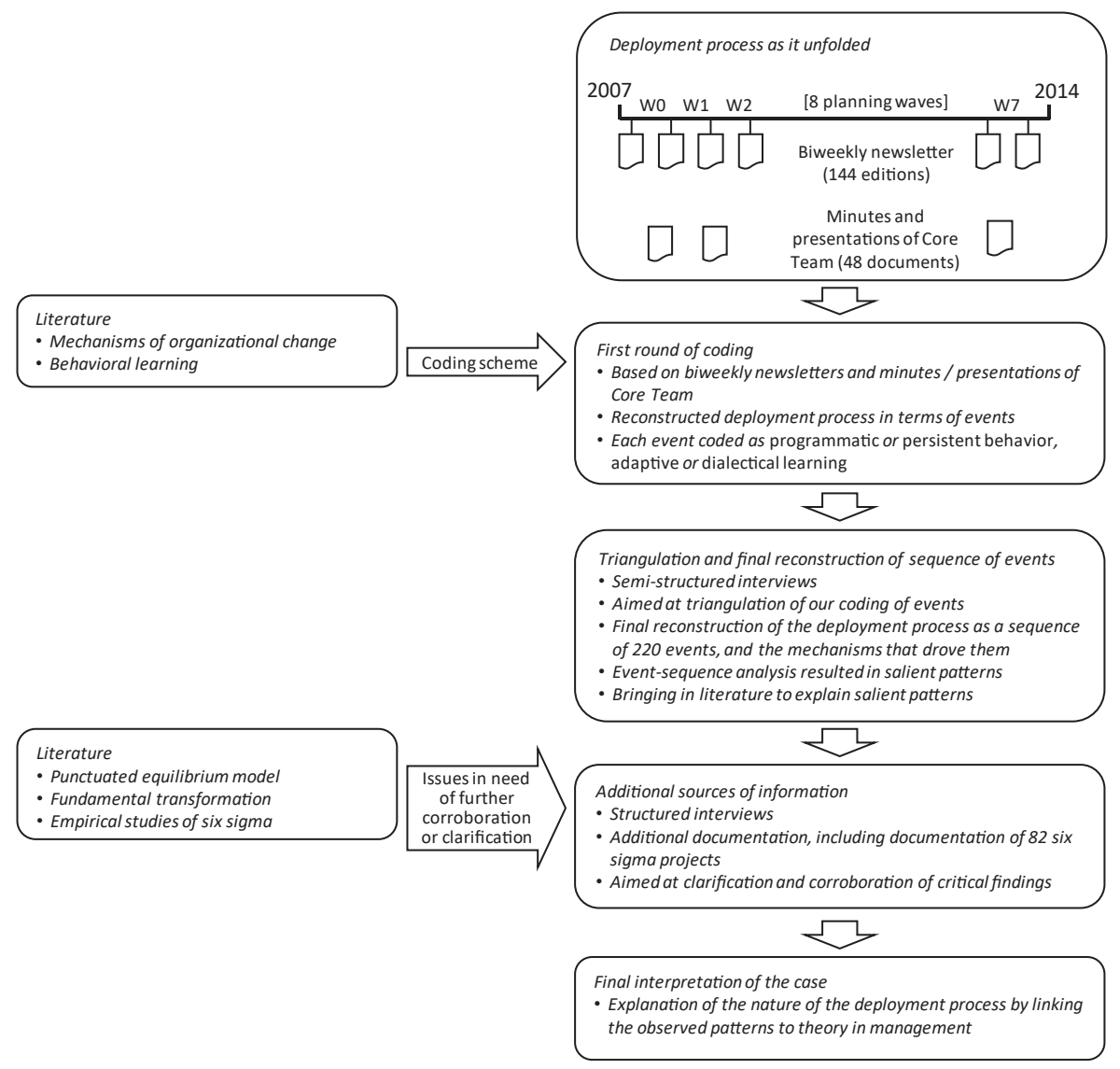

$\begin{array}{r}\text { Learning } \\ \text { mechanisms in } \\ \text { system } \\ \text { implementation } \\ \mathbf{9} \\ \hline\end{array}$

Figure 1.

Overview of the research process

(3) Responses (A2): whether the ensuing course of action amounted to a continuation of earlier plans, policies or initiatives (continuation) or represented something fundamentally new (change).

Each event was reconstructed following the above action (A1)-outcome (O1)-response (A2) sequence and then coded in terms of the four patterns discussed earlier: programmatic behavior, persistent behavior, adaptive learning or dialectical learning. For events coded as dialectical or adaptive learning, we also analyzed what it was that EuroDiv had learned and categorized these new insights by the domain of organizational activity to which they pertain. Romanelli and Tushman (1994), Miller and Friesen (1980) and Huber and Glick (1993) have developed major categories of an organizational change effort. Drawing on these works, we used the following categories:

(1) Strategy: EuroDiv's strategic goals and focus and programs to get there.

(2) Organizational structures: allocation of tasks to departments and positions; procedures processes and systems.

(3) Management and people: behaviors and styles of managers; human resources (HR) management. 
IJOPM

42,13

10

(4) Values: core values and beliefs in the organization.

(5) Six Sigma: management of the process improvement projects, Six Sigma courses, tools and Six Sigma procedures.

To mitigate participant-observer bias in assessing the events, the coding procedure was executed twice, both by the first and second author. Conflicting coding results were resolved by discussing the particular event and reaching consensus about the interpretation of it. We grouped events chronologically in the planning waves of the project leader training. Each wave of training is a key and highly visible deployment event, which establishes a natural subdivision of the deployment process into epochs. Our first analysis resulted in 220 reconstructed events (from Wave 0 in 2007 to Wave 7 in 2014). This is an example of a reconstructed event:

(1) Source: document [2.3].

(2) Action: "45 process improvement projects started in Waves 1 and 2."

(3) Outcome assessment: "Progress of projects difficult to manage", coded as Negative and Univocal.

(4) Response: "Improved structure for monitoring progress and scheduling reviews", coded as $\underline{\text { Change. }}$

(5) Event coded as: Adaptive learning (as the outcome was assessed univocally negative and the response was a change).

(6) Lessons learned: "How to monitor and manage the progress of projects", categorized as Six Sigma.

\subsection{Triangulation and corroboration of emerging interpretations}

During the first pass of analyzing the data, we kept a record of events and issues that were unclear. We then gathered additional evidence to corroborate and triangulate the data. We have particularly assured that our observations were validated by sources most central to the implementation to mitigate risks of lost recollections (given the fact that the reconstructed process ended in 2014). We took the following three steps to further assure the internal and external validity and reliability of the data (Gibbert et al., 2008).

3.4.1 During data analysis validation - semistructured interviews and additional archival data. We conducted semistructured interviews with the Six Sigma deployment leader and another member of the Six Sigma core team to corroborate our coding and reconstruction of the events. We verified factual statements about the company and the deployment of Six Sigma by requesting documented evidence for claims and stated facts. In particular, we got evidence of the claimed results of the Six Sigma initiative, such as statistics about the success and results of individual projects, written comments by customers, and we reviewed 82 completed Six Sigma process improvement projects for reported milestones and benefits realized.

3.4.2 After data analysis validation-structured interviews. After the first reconstruction of the sequence of events, we started identifying salient patterns and linking these to management theory. In order to corroborate our emerging interpretation of the implementation process, we collected further evidence:

(1) We conducted structured interviews with the Six Sigma deployment leader (1), another core team member (2), a black belt (3) and the director of technology (4). Interviewees were asked to articulate in detail their perception of what the company had learned, what the relative importance in this process was in terms of the four 
different patterns and whether they believe that the lessons could have been learned from external sources. Then, we asked interviewees to comment on our emerging interpretation and conclusions.

(2) In these interviews, we probed for instances of political and cultural conflict between factions in the organization and political and cultural misfit between Six Sigma and the organization (based on descriptions in Table 1 in Ansari et al., 2010).

While the first analysis and interviews were done in 2015 and 2016, these interviews took place in late 2016. Interviews lasted 60-90 min and resulted in eight source documents (consisting of four interview reports (IR1-4) and four documents consisting of responses to written questions). Here we also set up a system for documenting the evidence, where each source (archival documents; protocols, notes and transcripts of interviews; other documents) obtained a unique identifier and a reference to coded event(s) or finding (s). Also this coding scheme was modified a number of times, based on our emerging insights, by two authors. The changes in the last rounds of coding were minor (modifications in fewer than three events).

3.4.3 Participant-as-observer validation. Finally, one of the authors has extensive experience as a consultant in the field of Six Sigma in this type of high-tech companies. As a participant-as-observer (Gill and Johnson, 2002), this author provided training during the entire implementation process and therefore had acquired detailed and first-hand knowledge about the company, the people working in it and the events that occurred. This expertise (i.e. having learned and understood EuroDiv's symbolic world) (Delbridge and Kirkpatrick, 1994) was crucial in interpreting and evaluating the events that happened and the views that the actors expressed (cf. Langley et al., 2013). To assure objectivity and minimize participant observer bias (Delbridge and Kirkpatrick, 1994), archival data in the form of (1) progress report presentations on the initiative and (2) digital correspondence between the participantas-observer and the deployment leader, members of the core- and steering team and executive leadership members were subjected to a targeted search for instances that corroborated or falsified prevalent emerging interpretations.

\section{Case analysis and results}

The research objectives central to our reconstruction are to understand: "How does the process of implementing a QMS unfold over time? To what extent does the implementation process follow prescriptive learning mechanisms where they implement programmatic and turn-key recommendations, and to what extent does it follow constructive learning mechanisms where adaptations are developed to fit the organizational context?" In response, the view that emerges

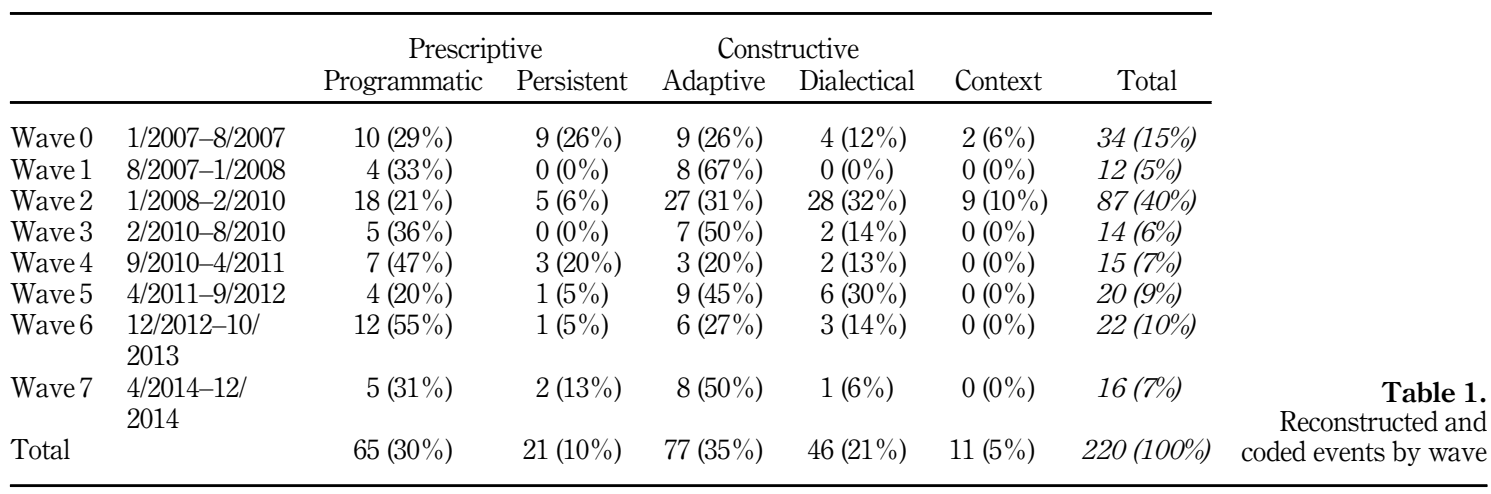


IJOPM

42,13

from our study sharply contrasts with existing portrayals of management system implementation processes. We characterize below how the implementation process at EuroDiv unfolded, and we link the emerging patterns to theories in the management literature that could be the basis for an alternative view on management system implementation, captured in propositions for future research.

\section{2}

\subsection{The roles of prescriptive versus constructive mechanisms in implementation}

In response to research question 1 and 2, Table 1 shows the numbers and frequencies of events that were coded as representing prescriptive mechanisms (programmatic or persistent) and constructive mechanisms (adaptive or dialectical) during each of the eight planning waves of implementing Six Sigma in EuroDiv from January 2007 to December 2014. As Table 1 shows, the implementation of Six Sigma at EuroDiv was consistently driven by both prescriptive and constructive mechanisms.

4.1.1 Prescriptive mechanisms - vicarious learning. Prescriptive mechanisms accounted for $40 \%$ (30\% programmatic and 10\% persistent behavior) of all the deployment events. This shows that in adopting a generic practice such as Six Sigma, EuroDiv learned many lessons in the implementation process by simple copy-and-paste behavior. Examples include the application of various QMS tools (e.g. design of experiments, critical-to-quality flowdown, measurement system analysis, failure mode and effect analysis) and the execution of standard format improvement projects (EuroDiv Newsletters, Wave 0-2, 6). Applying lessons originating from others' experience is sometimes also called vicarious learning (Huber, 1991; Noe et al., 2014). It is the traditional and perhaps most common form of learning in organizations, where employees passively acquire knowledge and skills deemed appropriate in the organization for direct transfer to their jobs (Noe et al., 2014). The main sources for vicarious learning of the deployment team at EuroDiv were consultants, the trainer of the courses, Six Sigma communities and other companies implementing Six Sigma. In cases where the adopted practices did not appear to work, the deployment team did not generally persist stubbornly. In fact, instances of the persistent behavior pattern were relatively rare, especially after Wave 0 (only 12 events were coded as persistent after Wave 0 ). Looking closer at coded instances of this pattern, we found no examples of persistent behavior driven by power dynamics or biases for negative feedback (cf. Van de Ven et al., 2019). This finding was corroborated by the structured interviews: "we are all deeply committed to designing good products, most our management has been working as an engineer themselves, and therefore politics and legitimacy by mandate are a rare phenomenon" (EuroDiv Interviews, IR1, 2016). Rather, it was usually acknowledged that a course of action was not working well, but either nobody came up with a plausible solution or more often, there were too many other issues for the deployment team to address; therefore, issues were simply abandoned for lack of time. For example, in Wave 5, it became clear that momentum for the Six Sigma projects was declining due to increased daily workload of the project leaders. As there was no clear idea about how to go about this, company management decided to initially do nothing (EuroDiv Newsletter, Wave 5).

4.1.2 Constructive mechanisms - adaptive learning. Table 1 reveals, however, that constructive mechanisms account for $56 \%$ of all deployment events. The deployment team often applied adaptive learning (35\% of deployment events), where they tried out aspects of the Six Sigma system, observed how it went and adjusted accordingly. For example, adoption of a model to evaluate project success or the standard format for project reviews were amended after it was concluded these did not work (EuroDiv Quarterly management update, Wave 0; Newsletter, Wave 2). For some aspects, such as the procedures and documents for the project reviews, EuroDiv went through as many as a dozen iterations (EuroDiv Interviews, IR3, 2016). Many instances of adaptive learning occurred in response 
to (partial) misfits between standard Six Sigma practices and the organization's needs, goals or structures. In such cases, EuroDiv first had to learn that there was a misfit and then had to learn how the practice should be adjusted to fit the situation at EuroDiv. Some of the Six Sigma techniques that the company adopted ultimately required adjustments so specific for EuroDiv that it is unlikely that they could have been copied from generic sources (e.g. Failure mode and effect analysis, design of experiments and standardized project templates (EuroDiv Newsletters, Wave 2, 3, 5, 6). It is likely that a general method such as Six Sigma needs situation-specific adaptations; therefore, its adoption implies a process of adaptive learning. This is consistent with studies of the diffusion and adaptation of practices (Ansari et al., 2010; Rerup and Feldman, 2011; Bresman, 2013) and is driven by a trade-off between a practice's generality versus its specificity and usefulness (Fensel and Motta, 2001; De Mast and Lokkerbol, 2012).

Adaptive learning was not limited to Six Sigma's techniques. To achieve their goal, EuroDiv learned that it should not restrict Six Sigma to product development alone, and the training courses became a tailor-made hybrid between Six Sigma and design for Six Sigma. Also, EuroDiv found that they needed to improve their skills in project management, and by trial and error, they developed effective structures for managing the progress of projects. Adaptive learning also occurred when prescriptions in the Six Sigma literature were not operational and specific enough to allow for easy copying. Six Sigma principles such as "stop nonurgent projects" and "decisions should be based on evidence" are abstract and complex and EuroDiv needed go through learning cycles to discover how to translate them to tangible behaviors and structures. For example, confrontation with nonurgent projects was observed multiple times, but only from Wave 2 onwards it was decided that these will be terminated (EuroDiv Newsletters, Wave 2; EuroDiv Interviews, IR1, 2016). The complexity of some of the skills that EuroDiv needed to learn made it unlikely that an organization could master them in a prescriptive fashion.

4.1.3 Constructive mechanisms - dialectical learning. Instances of dialectical learning were rarer than adaptive learning ( $21 \%$ of all deployment events). Dialectical confrontations and political tensions at EuroDiv were rare and mild, and in general, Six Sigma's principles and values were embraced. For example, in Wave 2, there was a general consensus that the efforts to improve quality did not yield enough result. In response, after several iterations it was decided to recognize Six Sigma projects more explicitly (EuroDiv Quarterly management update, Wave 2; EuroDiv Interviews, IR4, 2016). A plausible explanation for this was a noteworthy broker role (Burt, 2004) performed by the deployment leader and one of his core team colleagues, in moderating conflicts when they arose, synthesizing ideas and functioning as catalysts to the learning process. This was corroborated by the core team member: "halting project progress lasted (too) long, in hindsight we had better address this issue sooner multilaterally instead of trying to solve this bilaterally with all individual project sponsors" (EuroDiv Interviews, IR2, 2016).

Based on our findings and the pattern that emerges from our reconstruction presented above, we propose that the process of QMS implementation is driven as much by unforeseen events requiring idiosyncratic adaptive and dialectical learning as by programmatic implementation of generic prescriptions.

\subsection{Evolution of the implementation process}

To better understand the identified change mechanisms in response to research question 1 and 2, Table 1 and the following qualitative analysis of the underlying events reveal how these change mechanisms evolved over the course of eight waves.

4.2.1 Waves $0-2$ - building up of tension. Waves 0 and 1 were characterized by a rather optimistic deployment following prescriptive patterns. As these first two waves of Six Sigma 
IJOPM

42,13

projects progressed, however, it became apparent that the organization struggled to get projects completed and deliver substantial results. The core team invested great effort in improving the organization's project management structures, but apparently, such interventions were not nearly penetrating or powerful enough. Then, in Wave 2, there was a thickening of events (87 events in Wave 2, against on average 19 events in the other waves), and a lot of dialectical conflict took place (32\% of the events in Wave 2 were coded dialectical learning, against $12 \%$ and $0 \%$ in the previous waves). The deployment seemed stuck, makeshift solutions were no longer accepted and the company seemed to confront the core of problems and not to shy away anymore from tough measures. Exemplary topics include the organization of project reviews, the role of leadership for momentum in projects and the monitoring and managing of project progress (EuroDiv Newsletters, Wave 2; Quarterly management updates, Wave 2). From Wave 3 onwards, based on a new vision and with essential modifications in organizational structures in place, learning again proceeded in a more incremental manner and with less dialectical learning.

4.2.1.1 Punctuated equilibrium. We recognize the punctuated equilibrium model of Tushman and Romanelli (1985) and Romanelli and Tushman (1994) in this pattern of events. This model states that organizations tend to be in an inert state of equilibrium. Attempts to develop the organization by incremental and isolated initiatives, pertaining to only a few domains of organizational activity, do not really accumulate in substantial change, and instead, the organization remains in the equilibrium state. When sufficient pressure and urgency build up, a burst of discontinuous changes may be triggered, which involve nearly all key domains of organizational activity, and these bursts achieve substantial transformation of the organization. This model suggests that the implementation of Six Sigma begins in an equilibrium state. Equilibrium states are constrained by a set of fundamental choices and notions called deep structures (Tushman and Romanelli, 1985; Tushman et al., 1986; Gersick, 1991), such as core values and beliefs, strategic choices, power dynamics, habits and styles of managers, and organizational routines and structures. These deep structures cause the organization to behave like a complex system in equilibrium and with a high level of inertia. Changing organizations in equilibrium state is a complex process, as small changes tend to be neutralized or smothered by these deep structures unless the wider tangle of deep structures is changed as well.

4.2.1.2 Events leading to building up of tension. At EuroDiv, equilibrium behavior manifested itself in Waves 0,1 and 2. The easy things happened, such as training and starting Six Sigma projects, but the changes that really mattered were much more difficult to achieve: most of the improvement projects stagnated, it appeared difficult to change core organizational routines towards more engineering rigor and big-impact results failed to materialize. Although the core team iteratively learned to manage the progress of the Six Sigma projects by improving the management structures, the problem turned out to be stubborn, and the core team found it difficult to understand why it was so difficult to achieve progress (participant-as-observer correspondence with deployment leader, 2009).

As explained in the research methods section, we have categorized the lessons that EuroDiv learned by the domain of organizational activity that the new insights pertain to. Table 2 reveals that in Waves 0 and 1, the lessons learned were largely restricted to the QMS, and this reflects that attempts by the core team to get the Six Sigma initiative going were confined to the practices and procedures of Six Sigma itself. However, implementation of Six Sigma proved dependent on and intertwined with other domains of activity: EuroDiv's management styles, its inability to focus its activities and its values and beliefs posed impediments to the implementation of Six Sigma. Incremental attempts to implement Six Sigma without also fundamentally changing these other organizational characteristics turned out to be futile. For example, the issue of project progress was already observed in the first wave (EuroDiv Quarterly management updates, Wave 0). This is an essential 
notion in the punctuated equilibrium model, which predicts that, because of such deep and self-sustaining interdependencies, transformations do not happen when change initiatives are restricted to a limited number of organizational domains (Tushman et al., 1986; Romanelli and Tushman, 1994).

Over the course of Waves 1 and 2, tension started to build, as more and more project leaders were trained, but the projects continued to stagnate, results failed to appear and the remedies that the deployment team tried in order to get the projects going did not work. For example, monitoring mechanisms were installed, project coaching was introduced or project charter templates were amended (EuroDiv Newsletter, Wave 1; Quarterly management update, Wave 0). The punctuated equilibrium model assumes that such a build-up of pressure and urgency is required to overcome the forces that sustain the equilibrium and initiate deeper changes of a more radical nature.

When tension had built up sufficiently, a burst of rapid and radical changes occurred in Wave 2. For example, group leaders that acted as project sponsors were assigned explicit project responsibility (EuroDiv Newsletters, Wave 2; Quarterly management update, Wave 2), and a new organizational structure for the deployment was installed (EuroDiv Quarterly management updates, Wave 2). Besides the much larger number of events in Wave 2, the dynamics were also different in that the dialectical learning pattern occurred much more frequently (see Table 1), which is a sign of conflict, confusion and a break-down of the status quo. As reported by the director of technology: "after multiple steering committee discussions we ultimately realized that projects are not to be seen as on-top-off normal everyday work, but must be considered a core element and we need to assign priorities instead of delegating this to the project leaders" (EuroDiv Interviews, IR4, 2016).

4.2.1.3 Range of dimensions subject to change. Moreover, the new insights that the deployment team acquired were not limited to Six Sigma itself, as they had been until then, but pertained to a wide range of organizational activity. Table 2 quantifies the spread of learned lessons over the five domains of activity by the entropy of the rows, which is a statistical measure for the dispersion of classifications (Harris, 1988). For five categories, entropy ranges from 0.00 (when all classifications are concentrated in a single category, as in Wave 1) to 1.61 (when classifications are dispersed uniformly over the five categories). Note in Table 2 that entropy is large in Wave 2 (1.25 against a potential maximum value of 1.61 ), reflecting that deployment in Wave 2 was addressing a wide range of domains. This is in line with the punctuated equilibrium model, which predicts that the bursts of radical, discontinuous change that transforms an organization involve change on (nearly) all of the key dimensions of organizational activity (Romanelli and Tushman, 1994).

4.2.1.4 Deep structures underlying the building up of tension. EuroDiv learned that a big impediment to the success of its Six Sigma initiative was the lack of focus in its activities. Priorities in EuroDiv were diffuse and changed rapidly, and consequently, the company had a

\begin{tabular}{|c|c|c|c|c|c|c|c|c|}
\hline & Strategy & Structure & Management & Values & Six sigma & Totals & Entropy & \\
\hline Wave 0 & 0 & 1 & 0 & 3 & 26 & 30 & 0.47 & \\
\hline Wave 1 & 0 & 0 & 0 & 0 & 15 & 15 & 0.00 & \\
\hline Wave 2 & 14 & 8 & 15 & 8 & 62 & 107 & 1.25 & \\
\hline Wave 3 & 1 & 0 & 4 & 0 & 12 & 17 & 0.75 & \\
\hline Wave 4 & 1 & 0 & 0 & 0 & 14 & 15 & 0.24 & Table 2 \\
\hline Wave 5 & 2 & 2 & 4 & 1 & 16 & 25 & 1.11 & Domains of change and \\
\hline Wave 6 & 0 & 0 & 1 & 1 & 22 & 24 & 0.34 & the degree of \\
\hline Wave 7 & 0 & 2 & 1 & 0 & 11 & 14 & 0.66 & dispersion (entropy) \\
\hline Total & 18 & 13 & 25 & 13 & 178 & 247 & & over the domains \\
\hline
\end{tabular}


IJOPM

42,13

habit of starting large numbers of new projects and initiatives every month, thereby starving earlier initiatives from resources and ultimately bringing only a small fraction of its initiatives to completion. The stagnation of the Six Sigma projects put the issue on the agenda with urgency, and in response, EuroDiv's management established focal points that activities should concentrate on and aligned these decisions with group leaders and generally throughout the company. As a result, it became easier for the project leads to concentrate their efforts long enough to see projects to completion.

The core team also learned somewhere during Wave 2 that the laissez-faire style of management of group leaders was an impediment. Group leaders, whom the project leads report to, should assume a much more active role in coaching and adopt a much more decisive management style. Group leaders were taught the principle to either invest time in a project or else stop it and to avoid muddling on. For example, the "Enable or Stop" maxim was offered to project sponsors (EuroDiv Interviews, IR1, 2016). Furthermore, the company learned that they were rewarding a reactive instead of a proactive attitude towards reliability problems, and they started an initiative to change the underlying values and beliefs. These examples illustrate how an interrelated tangle of entrenched patterns, reaching far wider than the Six Sigma initiative, became transformed in Wave 2. In retrospect, many of these issues were known in the organization, and some of the lessons learned, such as the importance of focus and aligned reward systems, reflect insights that most managers will be familiar with. And yet, it had proved difficult to decisively tackle each of these issues in isolation and without the mounted tension created by the stagnating Six Sigma effort.

4.2.2 Waves 3-7-ongoing incremental changes. The radical improvements in Wave 2 set the stage for developments in later waves. They made a big difference, and projects began to gain momentum. Waves 3 and 4 were more incremental, both in terms of numbers of events (Table 1) and the concentration of new insights on the domain of Six Sigma itself (Table 2). Wave 5, however, reveals another episode where insights spanned nearly all domains of organization activity (entropy is 1.11), but without the same burst of events as in Wave 2 (only 20 events). In addition, $30 \%$ of the events in Wave 5 involved dialectical learning. The changes in this wave appear a reaction to tension that had started to build up in Wave 4, where projects again started to stagnate. For example, rather than changing procedures again, top management team directly put pressure on champions and project leaders and vigorously enforced the "Invest time or Stop" adage (EuroDiv Quarterly management update, Wave 5).

4.2.2.1 Recurring pattern of converging and diverging range of dimensions subject to change. In general, we observed a reoccurring pattern of convergence and divergence in the Six Sigma deployment process at EuroDiv. In convergence periods, in Waves 0-1, 3-4 and 6-7, there was little conflict, and dialectics and learning were restricted to a narrow domain of subjects. But in the divergent cycle, there was more dialectical conflict, learning involved a much wider range of subjects and changes were more fundamental and affected deep structures. The divergent phases reflected a branching out and expansion of implementation activities in new directions (Dooley and Van de Ven, 2017). They can be thought of as epochs of high dimensional change where a number of factors are at work (Dooley and Van de Ven, 1999). After the periods of divergence, there were more extended periods of convergence, with more consensus and a narrower focus on the implementation. The convergence periods had much lower dimensionality of change where fewer factors were at work (reflected in lower entropy in Table 2). Sustaining the deployment effort involves oscillating between these modes of change. Focusing too much on convergence results in not addressing deep underlying issues that can undermine the deployment effort. Focusing too much on divergence can undermine the efficiency of the deployment process. It is important to note that the magnitude of the divergent Wave 5 is smaller than Wave 2 , suggesting a deamplifying cycle of divergence and convergence over time. 
In retrospect of our findings and the dynamics that appeared from our reconstruction presented above we propose that the process of QMS implementation follows the pattern of a punctuated equilibrium, with alternating periods of incremental adaptation and periods of transformational changes.

\section{Discussion}

In this section, we discuss the predominant insights derived from our process study and how these relate or advance existing beliefs about (quality) management system implementation.

\subsection{Depth and nature of change}

Originally, EuroDiv perceived Six Sigma as a set of tools and skills, which could be adopted incrementally and which would enable the company to "guarantee low ppms." Our reconstruction revealed the changes in EuroDiv did not occur incrementally, as discussed above, and the wide-reaching changes implemented in and directly after Wave 2 went far beyond the technical tools and skills of Six Sigma itself. The findings suggest that implementing QMSs is not an add-on or a template of best practices that are integrated in an organization's existing deep structures. Instead, realizing Six Sigma's mission and turning the new skills into results requires a more fundamental change in an organization's deep structures themselves because these deep structures would otherwise become impediments that would ultimately hamper Six Sigma in achieving its goals. Adopting Six Sigma at EuroDiv was not a change in the system, but a change of the system (Tushman et al., 1986). Such pervasive changes are called fundamental transformation by Romanelli and Tushman (1994) and strategic change by Nadler et al. (1995). The deep structures that need to be fundamentally transformed are often hidden when a Six Sigma initiative starts, and implementing Six Sigma exposes them or even amplifies them. At EuroDiv, transformed deep structures include the company's inability to focus its activities, the laissez-faire style of management and the implicit rewarding of reactive behavior.

Scientific studies of success factors for Six Sigma implementation found other examples of deep structures that need to be addressed. Anand et al. (2009) and McAdam and Lafferty (2004) emphasize that Six Sigma's ambitions necessitate a supportive organizational infrastructure and that interdependencies among elements of such infrastructure may make an implementation focusing on only a narrow selection of them ineffective. They identify complex people (HR), process and information technology (IT) infrastructure issues that must be addressed. Arumugam et al. (2014) and Linderman et al. (2010) found that a culture which values data-based decision-making, and a focus on customers is a critical success factor for Six Sigma. It follows that if an organization's deep structures do not support such values, a successful implementation requires a transformation to the organization's values and beliefs system.

\subsection{The role of learning in implementation processes}

The role of learning is underemphasized in both organizational change literature (Stouten et al., 2018) and in a stream of research about the transfer of knowledge by copying practices from a blueprint or template (Jensen and Szulanski, 2007; Kent and Siemsen, 2018). Although these studies discuss the need of adapting practices to improve the fit with the environment where they are adopted, they do not actually trace how this process of adaptation unfolds over time nor do they describe the learning mechanisms that drive this adaptation process. Also, the forms of learning recognized in studies such as Winter et al. (2012) and Danese et al. (2017) are restricted to vicarious learning when employees learn to work with the new 
IJOPM

42,13

practices, and the more transformational learning discussed in our reconstruction is entirely absent.

As this study found, in the first few waves, the anticipated results of the initiative may be smothered by equilibrium behavior. This phenomenon could explain the finding of Swink and Jacobs (2012) that it takes at least 2-3 years before the benefits of Six Sigma become manifest. It probably requires a few initial waves in which the organization learns about Six Sigma and also becomes aware of its own deep structures that may hamper it and invents ways of overcoming them. We also believe that such radical transformations, confronting possibly sensitive impasses and challenging the status quo are difficult to achieve without a build-up of tension and urgency. The persistent problems and stagnation in Waves 0,1 and 2 at EuroDiv may have been needed in order to create sufficient tension to break the status quo. This required build-up of tension could explain some other phenomena, reported in the QM literature. Arumugam et al. (2014) and Linderman et al. (2010) stress that Six Sigma implementation needs top management leadership, and Swink and Jacobs (2012) found that loss-making firms benefit more from Six Sigma than firms that perform well, speculating that poor financial performance creates urgency for change. If Six Sigma implementation requires fundamental change of an organization's deep structures, and if such transformation occurs in a punctuated equilibrium pattern, then the need to overcome an equilibrium state would explain why the leverage of top management involvement and the urgency created by poor financial performance correlate positively with success of Six Sigma implementation.

\section{Conclusion}

This research presents an extensive process study of QMS implementation, which we analyzed by making an event sequence reconstruction of the unfolding implementation process and the mechanisms that drove it.

Contrary to the status quo depicted in the literature, this process study reveals that implementing QMSs requires a more radical transformation, where the organization discovers and alters impediments in the organization's deep structures. The study reveals the roles of various patterns of learning and nonlearning behavior in this process. In this case, $40 \%$ of the events driving the implementation process involved following the prescriptions of experts and well-established bodies of knowledge. However, $56 \%$ of events involved constructive mechanisms where the organization developed new insights itself by following the patterns of adaptive or dialectical learning.

\subsection{Contributions to theory}

Few studies in operations management have undertaken a process study, and most of the research into Six Sigma or alternative QMS implementation is dominated by variance studies (e.g. Linderman et al., 2006; Anand et al., 2009; Nair et al., 2011; Zhang et al., 2012; Easton and Rosenzweig, 2012; Jacobs et al., 2015). Although these studies give valuable insights into various factors and variables that influence implementation success, none of them provide a description and theory of how firms actually implement QMSs. We show that the realities of how the deployment process unfolds significantly deviate from existing prescriptions. We view the deployment of Six Sigma as learning process and studied the different types of learning that occurred during each deployment epoch. We find these events have a pattern which follows a punctuated equilibrium model.

Furthermore, studies by Stouten et al. (2018) and Bamford and Daniel (2005) discuss disputes and controversies in the literature on organizational change, concluding that consensus is lacking regarding basic change processes. Mentioning the punctuated equilibrium model as a "less recognized alternative change model," the mainstream as 
discussed in these papers follows the programmatic view. It is generally acknowledged that effective change involves learning new skills and knowledge, but Stouten et al. (2018) observe that only one out of the seven change models they discuss incorporates the role of learning explicitly. The given models pay little attention to how and when learning should occur. Beer et al. (1990)'s study is a rare example which discusses the importance of adjusting the course and plans as the implementation process progresses. None of the models discussed in Stouten et al. (2018) acknowledge that learning could go far beyond adjustments to the generic program or template being implemented and could extend to learning about deep structures in the organization itself, as observed in developing our reconstruction.

\subsection{Implications for practice}

In contrast with the extant practitioners' literature, our case suggests that advice for managing the implementation process should not strictly be programmatic and follow generic templates, but instead, should be aimed at teaching deployment leaders how to manage and navigate a learning process that cannot be fully charted from the start. EuroDiv's journey is consistent with the view of Tushman and Romanelli (1985, p. 208) that "organizations do not evolve through a standard set of stages"; much of what an organization needs to learn is idiosyncratic for the organization and needs to be discovered by the deployment leaders themselves moving through learning cycles. In planning for an implementation effort, managers may have the mistaken belief that they can buy Six Sigma "off the shelf" or hand over the implementation to consultants. Our study, to the contrary, suggests that such processes demand quite a lot from the organization's own resources, resourcefulness and perseverance and that executive leadership is needed in many junctures in the change effort.

Implementing QMSs provides important organizational learning opportunities that may be much more than the direct functionality of its tools and techniques. EuroDiv became aware of some of its entrenched patterns and habits that had been hampering the organization before, and they came to understand the deeper structures that drove them. The deployment of Six Sigma became an occasion to change some of these structures for the better, and the impact of the initiative was much wider than the immediate improvement of product reliability. Our findings may help deployment leaders to reframe stagnation and confusion. Instead of perceiving them as a problem, a marker of failure or resistance to change, deployment leaders may recognize how they are part of the dialectical learning that helps the organization to become aware of deep impediments.

\subsection{Limitations}

Although this research builds on a rich collection of field data, several limitations must be noted. The case study considered a single firm's implementation. The implementation processes in various organizations are idiosyncratic and differ in many aspects. This presents the main limitation of our conclusions in which the study identifies the mechanisms that drive the dynamics of implementation processes, but it cannot predict how individual processes will unfold and what the roles and relative importance of various mechanisms in individual processes will be.

Comparisons of our findings with those in related studies in the literature provide some insights on context conditions. For example, possible context conditions may be the organization's culture, conflict management and power balance. Canato et al. (2013) examined the failed attempts to implement Six Sigma at 3M, which they report as having a culture of radical innovation that clashed with Six Sigma's values of rigor and control. In contrast, EuroDiv has an engineering culture and is active in the automotive industry, which has a long history and culture of control and rigor when it comes to quality and reliability. It also managed conflicts and complaints through the core team leader who managed and resolved 
IJOPM 42,13

disagreements internally without exposing them externally to other parts of the organization, and as discussed earlier, political tensions were relatively mild. In contrast, a process study of integrating a health care system by Van de Ven et al. (2017) found that most conflicts were resolved by the more powerful parties imposing their views on the less powerful, resulting in no learning. Different factors such as politics and power dynamics may play a bigger role elsewhere than was observed in this firm. Such tensions may be more difficult to resolve, especially during critical dialectical learning.

\section{References}

American Society for Quality (2021), "What is a quality management systems?”, available at: https:// asq.org/quality-resources/quality-management-system\#Standards (accessed 12 October 2021).

Anand, G., Ward, P.T., Tatikonda, M.V. and Schilling, D.A. (2009), "Dynamic capabilities through continuous improvement infrastructure", Journal of Operations Management, Vol. 27 No. 6, pp. 444-461.

Ansari, S.M., Fiss, P.C. and Zajac, E.J. (2010), "Made to fit: how practices vary as they diffuse", The Academy of Management Review, Vol. 35 No. 1, pp. 67-92.

Argote, L. and Miron-Spektor, E. (2011), "Organizational learning: from experience to knowledge", Organization Science, Vol. 22 No. 5, pp. 1123-1137.

Arumugam, V., Antony, J. and Linderman, L. (2014), "A multilevel framework of Six Sigma: a systematic review of the literature, possible extensions, and future research", Quality Management Journal, Vol. 21 No. 4, pp. 36-61.

Bamberger, P.A. (2018), "AMD — clarifying what we are about and where we are going”, Academy of Management Discoveries, Vol. 4 No. 1, pp. 1-10.

Bamford, D. and Daniel, S. (2005), "A case study of change management effectiveness within the NHS”, Journal of Change Management, Vol. 5, pp. 391-406.

Beer, M., Eisenstat, R.A. and Spector, B. (1990), "Why change programs do not produce change", Harvard Business Review, Vol. 68, pp. 158-166.

Bhamu, J. and Sangwan, K.S. (2014), "Lean manufacturing: literature review and research issues", International Journal of Operations and Production Management, Vol. 34 No. 7, pp. 876-940.

Boonstra, J. (Ed.) (2008) Dynamics of Organizational Change and Learning, John Wiley and Sons, New York, NY.

Braunscheidel, M.J., Hamister, J.W., Suresh, N.C. and Star, H. (2011), "An institutional theory perspective on Six Sigma adoption", International Journal of Operations and Production Management, Vol. 31 No. 4, pp. 423-451.

Bresman, H. (2013), "Changing routines: a process model of vicarious group learning in pharmaceutical R\&D”, Academy of Management Journal, Vol. 56 No. 1, pp. 35-61.

Burt, R.S. (2004), "Structural holes and good ideas", American Journal of Sociology, Vol. 110 No. 2, pp. 349-399.

Canato, A., Ravasi, D. and Phillips, N. (2013), "Coerced practice implementation in cases of low cultural fit: cultural change and practice adaptation during the implementation of Six Sigma at 3M", Academy of Management Journal, Vol. 56 No. 6, pp. 1724-1753.

Chakravorty, S.S. (2009), "Six Sigma programs: an implementation model", International Journal of Production Economics, Vol. 119 No. 1, pp. 1-16.

Chakravorty, S.S. and Atwater, J.B. (1996), “A comparative study of line design approaches for serial production systems”, International Journal of Operations and Production Management, Vol. 16 No. 6, pp. 91-108.

Danese, P., Romano, P. and Boscari, S. (2017), "The transfer process of lean practices in multi-plant companies", International Journal of Operations and Production Management, Vol. 37 No. 4, pp. $468-488$. 
De Mast, J. and Lokkerbol, J. (2012), "An analysis of the Six Sigma DMAIC method from the perspective of problem solving”, International Journal of Production Economics, Vol. 139 No. 2, pp. 604-614.

Delbridge, R. and Kirkpatrick, I. (1994), "Theory and practice of participant observation", in Wass, V. and Wells, P. (Eds), Principles and Practice in Business and Management Research, Dartmouth, Aldershot, pp. 35-62.

Dooley, K. and Van de Ven, A.H. (1999), "Explaining complex organizational dynamics", Organization Science, Vol. 10 No. 3, pp. 358-372.

Dooley, K. and Van de Ven, A.H. (2017), "Cycles of divergence and convergence: underlying processes of organization change and innovation", in Langley, A. and Tsoukas, H. (Eds), The Sage Handbook of Process Organization Studies, Sage, Thousand Oaks, CA, pp. 574-590.

Easton, G.S. and Rosenzweig, E.D. (2012), "The role of experience in Six Sigma project success: an empirical analysis of improvement projects", Journal of Operations Management, Vol. 30 Nos 7/8, pp. 481-493.

Easton, G.S. and Rosenzweig, E.D. (2015), "Team leader experience in improvement teams: a social networks perspective”, Journal of Operations Management, Vol. 37, pp. 13-30.

Fensel, D. and Motta, E. (2001), "Structured development of problem solving methods", IEEE Transactions on Knowledge and Data Engineering, Vol. 13 No. 6, pp. 913-932.

Gersick, C.J.G. (1991), "Revolutionary change theories: a multilevel exploration of the punctuated equilibrium paradigm", Academy of Management Review, Vol. 16 No. 1, pp. 10-36.

Gibbert, M., Ruigrok, W. and Wicki, B. (2008), "What passes as a rigorous case study?", Strategic Management Journal, Vol. 29 No. 13, pp. 1465-1474.

Gill, J. and Johnson, P. (2002), Research Methods for Managers, 3rd ed., Sage, London.

Hammer, M. (2004), "Deep change: how operational innovation can transform your company", Harvard Business Review, Vol. 82 No. 4, pp. 84-93.

Harris, B. (1988), "Entropy", in Kotz, S. and Johnson, N.L. (Eds.), Encyclopedia of Statistical Sciences, 8th ed., Wiley, New York, NY, Vol. 2.

Hirzel, A.K., Leyer, M. and Moormann, J. (2017), "The role of employee empowerment in the implementation of continuous improvement: evidence from a case study of a financial services provider", International Journal of Operations and Production Management, Vol. 37 No. 10, pp. 1563-1579.

Huber, G.P. (1991), "Organizational learning: the contributing processes and the literatures", Organization Science, Vol. 2 No. 1, pp. 88-115.

Huber, G.P. and Glick, W.H. (1993), Organizational Change and Redesign: Ideas and Insights for Improving Performance, Oxford University Press, New York, NY.

Imai, M. (1986), Kaizen: the Key to Japanese Competitiveness Success, McGraw-Hill, New York.

Ivanova, A., Gray, J. and Sinha, K. (2014), "Towards a unifying theory of management standard implementation", International Journal of Operations and Production Management, Vol. 34 No. 10, pp. 1269-1306.

Jacobs, B.W., Swink, M. and Linderman, K. (2015), "Performance effects of early and late Six Sigma adoptions", Journal of Operations Management, Vol. 36, pp. 244-257.

Jensen, R.J. and Szulanski, G. (2007), "Template use and the effectiveness of knowledge transfer", Management Science, Vol. 53 No. 11, pp. 1716-2173.

Kent, P. and Siemsen, E. (2018), "Production process moves: template use and the need to adapt", Production and Operations Management, Vol. 27 No. 3, pp. 480-495.

Kerrin, M. (1999), "Continuous improvement capability: assessment within one case study organization", International Journal of Operations and Production Management, Vol. 19 No. 11, pp. 1154-1167. mechanisms in

system

implementation 
IJOPM

42,13

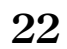

Lameijer, B., De Mast, J. and Does, R.J.M.M. (2017), "Lean Six Sigma deployment and maturity models: a critical review", Quality Management Journal, Vol. 24 No. 4, pp. 6-20.

Lameijer, B.A., Boer, H., Antony, J. and Does, R.J.M.M. (2021), "Continuous improvement implementation models: a reconciliation and holistic meta model", Production Planning and Control, pp. 1-20, doi: 10.1080/09537287.2021.1974114.

Langley, A., Smallman, C., Tsoukas, H. and Van de Ven, A.H. (2013), "Process studies of change in organization and management: unveiling temporality, activity, and flow", Academy of Management Journal, Vol. 56 No. 1, pp. 1-13.

Levitt, B. and March, J.G. (1988), "Organizational learning”, Annual Review of Sociology, Vol. 14, pp. 319-340.

Linderman, K., Schroeder, R.G., Zaheer, S. and Choo, A.S. (2003), "Six Sigma: a goal-theoretic perspective”, Journal Of Operations Management, Vol. 21 No. 2, p. 193.

Linderman, K., Schroeder, R.G., Zaheer, S., Liedtke, C. and Choo, A.S. (2004), "Integrating quality management practices with knowledge creation processes", Journal of Operations Management, Vol. 22 No. 6, pp. 589-607.

Linderman, K., Schroeder, R.G. and Choo, A.S. (2006), "Six Sigma: the role of goals in improvement teams", Journal of Operations Management, Vol. 24 No. 6, pp. 779-790.

Linderman, K., Schroeder, R.G. and Sanders, J. (2010), "A knowledge framework underlying process management”, Decision Sciences, Vol. 41 No. 4, pp. 689-719.

McAdam, R. and Lafferty, B. (2004), "A multilevel case study critique of Six Sigma: statistical control or strategic change?", International Journal of Operations and Production Management, Vol. 24 No. 5, pp. 530-549.

McLean, R.S., Antony, J. and Dahlgaard, J.J. (2017), "Failure of continuous improvement initiatives in manufacturing environments: a systematic review of the evidence”, Total Quality Management and Business Excellence, Vol. 28 Nos 3-4, pp. 219-237.

Miller, D. and Friesen, P.H. (1980), "Momentum and revolution in organizational adaptation", Academy of Management Journal, Vol. 23, pp. 591-614.

Mohr, L. (1982), Explaining Organizational Behavior, Jossey-Bass, San Francisco.

Nadler, D.A., Shaw, R.B. and Walton, A.E. (1995), Discontinuous Change: Leading Organizational Transformation, Jossey-Bass, San Francisco, CA.

Nair, A., Malhotra, M.K. and Ahire, S.L. (2011), "Toward a theory of managing context in Six Sigma process-improvement projects: an action research investigation", Journal of Operations Management, Vol. 29 No. 5, pp. 529-548.

Netland, T.H., Schloetzer, J.D. and Ferdows, K. (2015), "Implementing corporate lean programs: the effect of management control practices", Journal of Operations Management, Vol. 36, pp. 90-102.

Netland, T.H., Schloetzer, J.D. and Ferdows, K. (2021), "Learning Lean: rhythm of production and the pace of lean implementation", International Journal of Operations and Production Management, Vol. 41 No. 2, pp. 131-156.

Noe, R.A., Clarke, A.D.M. and Klein, H.J. (2014), "Learning in the twenty-first century workplace", Annual Review of Organizational Psychology and Organizational Behavior, Vol. 1, pp. 245-275.

Nonthaleerak, P. and Hendry, L. (2008), "Exploring the Six Sigma phenomenon using multiple case study evidence", International Journal of Operations and Production Management, Vol. 28 No. 3, pp. 279-303.

Ouchi, W.G. (1979), "A conceptual framework for the design of organizational control mechanisms", Management Science, Vol. 25 No. 9, pp. 833-848.

Pegels, C.C. (1984), "The Toyota production system-lessons for American management", International Journal of Operations and Production Management, Vol. 4 No. 1, pp. 3-11.

Peng, D.X., Schroeder, R.G. and Shah, R. (2008), "Linking routines to operations capabilities: a new perspective”, Journal of Operations Management, Vol. 26 No. 6, pp. 730-748. 
Pierce, N. and Rich, N. (2009), "Lean transformation in the pure service environment: the case of the call service center", International Journal of Operations and Production Management, Vol. 29 No. 1, pp. 54-76.

Poole, M.S. (2004), "Central issues in the study of change and innovation", in Poole, M.S. and Van de Ven, A.H. (Eds), Handbook of Organizational Change and Innovation, Oxford University Press, New York, NY, pp. 3-31.

Poole, M.S., Van de Ven, A.H., Dooley, K. and Holmes, M.E. (2000), Organizational Change and Innovation Processes: Theory and Methods for Research, Oxford University Press, New York, NY.

Powell, D.J. and Coughlan, P. (2020), "Rethinking lean supplier development as a learning system", International Journal of Operations and Production Management, Vol. 40 Nos 7/8, pp. 921-943.

Rerup, C. and Feldman, M.S. (2011), "Routines as a source of change in organizational schemata: the role of trial-and-error learning", Academy of Management Journal, Vol. 54 No. 3, pp. 577-610.

Romanelli, E. and Tushman, M.L. (1994), "Organizational transformation as punctuated equilibrium: an empirical test”, Academy of Management Journal, Vol. 37 No. 5, pp. 1141-1166.

Scherrer-Rathje, M., Boyle, T.A. and Deflorin, P. (2009), "Lean, take two! Reflections from the second attempt at Lean implementation”, Business Horizons, Vol. 52 No. 1, pp. 79-88.

Schroeder, R.H., Linderman, K., Liedtke, C. and Choo, A.S. (2008), "Six Sigma: definition and underlying theory", Journal of Operations Management, Vol. 26 No. 4, pp. 536-554.

Schwab, A. and Miner, A.S. (2008), "Learning in hybrid-project systems: the effects of project performance on repeated collaboration”, Academy of Management Journal, Vol. 51 No. 6, pp. 1117-1149.

Shafer, S.M. and Moeller, S.B. (2012), "The effects of Six Sigma on corporate performance: an empirical investigation”, Journal of Operations Management, Vol. 30 Nos 7/8, pp. 521-532.

Shewhart, W.A. (1931), Economic Control of Quality of Manufactured Products, Van Nostrand, New York; Macmillan, London.

Stouten, J., Rousseau, D.M. and De Cremer, D. (2018), "Successful organizational change: integrating the management practice and scholarly literatures", Academy of Management Annals, Vol. 12 No. 2, pp. 752-788.

Swink, M. and Jacobs, B.W. (2012), "Six Sigma adoption: operating performance impacts and contextual drivers of success", Journal of Operations Management, Vol. 30 No. 6, pp. 437-453.

Tenhiälä, A. and Helkiö, P. (2015), "Performance effects of using an ERP system for manufacturing planning and control under dynamic market requirements", Journal of Operations Management, Vol. 36, pp. 147-164.

Tichy, N.M. and Devanna, M.A. (1986), The Transformational Leader, John Wiley and Sons, New York, NY.

Tushman, M.L. and Romanelli, E. (1985), "Organizational evolution: a metamorphosis model of convergence and reorientation", in Cummings, L.L. and Staw, B.M. (Eds), Research in Organizational Behavior, JAI Press, Greenwich, Vol. 7, pp. 171-222.

Tushman, M.L., Newman, W.H. and Romanelli, E. (1986), "Convergence and upheaval: managing the unsteady pace of organizational evolution", California Management Review, Vol. 29 No. 1, pp. 29-44.

Van de Ven, A.H. (2007), Engaged Scholarship: A Guide for Organizational and Social Research, Oxford University Press, Oxford.

Van de Ven, A.H. and Poole, M.S. (1995), "Explaining development and change in organizations", Academy of Management Review, Vol. 20 No. 3, pp. 510-540.

Van de Ven, A.H. and Sun, K. (2011), "Breakdowns in implementing models of organization change", Academy of Management Perspectives, Vol. 25 No. 3, pp. 58-74. 
IJOPM

42,13

\section{4}

\section{Corresponding author}

Bart A. Lameijer can be contacted at: b.a.lameijer@uva.nl Management, Vol. 45 No. 3, pp. 1252-1283. pp. 672-685.
Van de Ven, A.H., Bechara, J.P. and Sun, K. (2019), "How outcome agreement and power balance among parties influence processes of organizational learning and non-learning", Journal of

Winter, S.G., Szulanski, G., Ringov, D. and Jensen, R.J. (2012), "Reproducing knowledge: inaccurate replication and failure in franchise organizations", Organization Science, Vol. 23 No. 3,

Zhang, D., Linderman, K. and Schroeder, R.G. (2012), "The moderating role of contextual factors on quality management practices", Journal of Operations Management, Vol. 30 No. 1, pp. 12-23.

$\mathrm{Zu}, \mathrm{X}$., Fredendall, L.D. and Douglas, T.J. (2008), "The evolving theory of quality management: the role of Six Sigma”, Journal Of Operations Management, Vol. 26 No. 5, pp. 630-650.

For instructions on how to order reprints of this article, please visit our website:

www.emeraldgrouppublishing.com/licensing/reprints.htm

Or contact us for further details: permissions@emeraldinsight.com 